\title{
INTEGRATED REPORTING AND IMPLICATIONS FOR ACCOUNTING CURRICULUM IN NIGERIA
}

\author{
Adzor Ibiamke * \\ Department of Accounting, Faculty of Management Sciences, Nigerian Defence \\ Academy, Kaduna \\ Clement C. M. Ajekwe \\ Department of Accounting, Faculty of Management Sciences, Benue State University \\ Makurdi
}

\begin{abstract}
Integrated reporting $(\langle I R\rangle)$ has been promoted by influential international organisations as the communication vehicle that provides concise, futureoriented and strategically relevant information and integrates financial, social and environmental elements to providers of the capitals and other interested parties. Increasing adoption of $\langle I R\rangle$ globally envisages significant implications for accounting education and the accounting curriculum, for both professional and academic training necessary for the "new" corporate reporting protocol. This paper reviews integrated reporting literature to access the principles and frameworks and outputs articulated by these influential organisations. In view of the suggested reporting outcomes, fundamental guiding principles and the main components of an integrated report, it is envisaged that the "new" accounting curricula would focus more on the longer-term than the shorter-term, more on corporate strategic outlook than operational or transactional processes; more prospective rather than retrospective analysis and reporting on wider business performance metrics than on narrower external financial reporting data or audit compliance. While leading global professional accountancy bodies (e.g., ACCA \& CIMA) have already fully incorporated integrated reporting principles within their curriculum at the professional level, only few universities outside Nigeria have incorporated integrated reporting principles or learning outcomes within their existing curriculum. The paper calls on Accounting Departments of universities to incorporate $\langle I R>$ principles into their course offerings.
\end{abstract}

KEYWORDS: Integrated reporting, sustainability, social responsibility, stakeholder engagement, accounting curriculum, Nigeria

\section{INTRODUCTION}

Corporate reporting has evolved considerately over the years to meet the changing needs of users consequent upon greater complexity in business models, changing policy responses to risk, financial crises and uncertainty coupled with heightened expectations for transparency, accountability and environmental concerns (Bekefi, Epstein \&Yuthas, 2008; Gökten\&Marşap, 2017).In particular, the traditional financial business reporting model has been challenged because it does not adequately satisfy the information needs of stakeholders for assessing a company's past and future performance (Flower, 2015). Currently, corporate financial reporting consists of backward-looking financial information (Beck, Dumay \& Frost, 2017; Camilleri, 2017; Crowther, 2016) which does not necessarily reveal the whole picture of the organisations' performance (Burritt 
\& Schaltegger, 2010).Furthermore, wealth creation as the basic reason for an organisation's existence is being questioned by the general public because this narrow focus excludes creating value or justice for people, society and the environment (Gray, 2006). In response to these concerns, integrated reporting $(<\mathrm{IR}\rangle)$ evolved as the communication vehicle to provide concise, future-oriented and strategically relevant information that integrates financial, social and environmental elements to providers of capitals and other interested parties.

The idea of recognising and reporting on social, environmental and economic elements or impacts gained prominence since the late 1990s to date. At least two factors or events have given impetus to this development: (i) the popularity of John Elkington's (1998) book Cannibals with Forks: The Triple Bottom Line of 21st Century Business, which started new non-financial reporting frameworks from a social and environmental perspective (Gray, 2006) and (ii) the formation in 2010 of the International Integrated Reporting Council (IIRC).The IIRC brought together a coalition of more than seventy international organizations (regulators, investors, companies, standard setters, the accounting profession and NGOs) with the common mission to make integrated reporting, i.e., an integration of financial and nonfinancial information in the same report, the global norm for companies. Frameworks and ideas such as triple bottom line reporting and integrated reporting were seen by academics, practitioners, leading professional accountancy and advisory bodies as a solution to deficiencies of traditional financial reporting (see Deloitte, 2011; Nixon \&Burns, 2012; Giovannoni \& Maraghini, 2013; de Villiers, Rinaldi \& Unerman, 2014; Adams \& Frost, 2008; Bhimani \& Langfield-Smith, 2007).

In particular, integrated reporting $(<\mathrm{IR}>)$ encourages companies to give readers "the bigger picture" of how they are operating and achieving value over the short, medium and long term. One of the main distinguishing features of integrated reporting is its aim to provide a "one report" (Eccles \& Krzus, 2010) that would indicate an organisation's most material, social, environmental and economic actions, outcomes, risks and opportunities in a manner that reflects the integrated nature of these factors for the organisation (IIRC, 2012; Eccles \& Krzus, 2010). An integrated report, output of integrated reporting, does not just put all corporate reporting into one publication, it is a journey in which a company communicates a clear, concise, integrated story explaining how stewardship is demonstrated and how value is created and sustained for all stakeholders. While integrated reporting is a legal requirement in some countries (e.g., South Africa), sixty-four other countries globally (e.g., USA, Japan, Brazil, UK, etc.) have voluntarily adopted integrated reporting. The number of countries voluntarily adopting <IR> is on the increase (IIRC, 2018; KPMG, 2017).

Increasing prominence and adoption of <IR> globally envisages significant implications for accounting education, both for professional qualifications and university accounting curriculum. In particular, $\langle\mathbb{I R}\rangle$, and the principles behind it, suggest an accounting curriculum, different from the traditional one, that includes learning outcomes that relate to providing a more holistic form of reporting value created by a business, by considering non-financial resources, such as human, social and intellectual as well as financial capitals. The implications of adopting <IR $>$ will 
include a change to the traditional structure of accounting programmes and how they are assessed.

The structure of the paper is as follows: in the next section several of the key developments in social and environmental reporting that prompted moves towards integrated reporting are explained. Section 3 summarises the key sources and elements of integrated reporting. Section 4 accesses implications of $\langle\mathrm{IR}\rangle$ on accounting curriculum; while section5 accesses integrated reporting in academic and professional education across the globe. Section 6 assesses sustainability and integrated reporting in Nigeria. While section 7 suggests how $<I R>$ could be incorporated into accounting curriculum of Nigerian universities, section 8 concludes the paper.

\section{Key Developments in Social and Environmental Reporting Prompting Moves Towards <IR>}

In the late 1990s the accounting profession saw the need for a shift away from the "stewardship" or "fiduciary" shareholder/investor perspective of financial reporting to a stakeholder perspective of corporate reporting. This period also saw developments in academic literature on accounting and accountability systems for the combined management and reporting of financial and non-financial performance. Academics and practitioners analysed the interaction between managements' strategic propositions, organisational control systems and performance measurement and reporting systems (Parker, 2012). Among several proposals advanced by scholars within the domains of accounting, management and governance (Nixon \& Burns, 2012; Giovannoni \& Maraghini, 2013), three frameworks emerged: Sustainability Reporting, the Balanced Scorecard and the Triple Bottom Line.

"Sustainability" refers to corporate activities that maintain or enhance the ability of the company to create value over the long term. Sustainability accounting reflects the governance and management of a company's environmental and social impacts arising from production of goods and services, as well as its governance and management of the environmental and social capitals necessary to create long-term value. Sustainability accounting helps organisations to set goals, measure performances, and manage change in order to make their operations more sustainable. A sustainability report conveys disclosures on an organisation's impact on the environment, society and the economy. In doing so, sustainability reporting makes abstract issues tangible and concrete, thereby assisting in understanding and managing the effects of sustainability developments on the organisation's activities and strategy (Global Reporting Initiative (GRI), 2015). In other words, sustainability reports can be used to reflect the impact and connection of economic, social and environmental factors.

The Balanced Scorecard (BSC) is an internal performance reporting, measurement and management control mechanism that integrates financial and non-financial strategic measures (Kaplan \& Norton, 1996). In doing so it aims to overcome the limits often associated with financial indicators; financial measures account for past performance while non-financial measures have the potential not only to drive future performance (Nørreklit, 2003) but also align individual or departmental goals with the overall strategic aims of the organisation through tangible outcomes and measures. 
Each organisation chooses measures considered appropriate by its managers for inclusion in the BSC. These measures focus management attention on the most important strategic and operational aspects of the organisation. Even though many, BSC measures financial outcomes as well as non-financial and forward looking measures which do not necessarily include social, environmental and sustainability issues. Hence, it is unlikely that the BSC measures will provide any form of integration between economic, social, governance and environmental measures.

Triple Bottom Line (TBL) is an external reporting method used in business accounting to further expand stakeholders' knowledge of the company. It goes beyond the traditional financial aspects and incorporates three dimensions of performance: social, environmental and financial with focus on the "people, planet, and profit (GRI, 2006; Elkington, 2004; Elkington, 1998; Adams, Frost \& Webber, 2004). It is a "concerted effort to incorporate economic, social, and environmental (or ecological) considerations into a company's evaluation and decision making processes" (Wang \& Lin, 2007). This type of reporting is important because it "captures the essence of sustainability by measuring the impact of an organization's activities on the world, including both its profitability and shareholder values as well as its social, human and environmental capitals (Savitz, 2006). It also establishes principles by which a company should concentrate on the total effect of their actions (Slaper \& Hall, 2011).The Triple Bottom Line reporting has a wide focus but it was developed over time hence it grew in an incoherent and possibly ad hoc stand-alone manner (silo approach) and was seldom articulate enough to guide organizational stakeholders in decision making. The Triple Bottom Line reporting is also said to be complex, lengthy, disjointed and less useful (Sridar \& Jones, 2012; Boje, 2016). Following these criticisms, several reporting organisations and regulatory bodies responded in recommending or adopting a more holistic approach known as integrated reporting $\langle\mathbf{I R}>$ : "a concise communication about how an organisation's strategy, governance, performance and prospects, in the context of its external environment, lead to the creation of value over the short, medium and long term" (IIRC, 2013:8). Under this approach, the different strands of reporting (financial, management commentaries, governance and remuneration and sustainability reporting) are combined into a coherent integrated report aimed at explaining to providers of capitals how an organisation creates and sustains value over time" (IIRC, 2013: 4).

\section{Key Elements of an Integrated Report}

In his section, key elements of an integrated report suggested in various discussion papers and frameworks are discussed and reviewed, including those from; (i) Global Reporting Initiatives (GRI), (ii)Initiatives from South African Integrated Reporting Committee (IRC), (iii) The Prince of Wales Accounting for Sustainability (A4S) Forum, (iv) International Accounting Institutions (IFAC\& IASB) and (v) International Integrated Reporting Council's (IIRC).

The Global Reporting Initiative (GRI) is a global multi-stakeholder network of people and organizations that collaborates to advance sustainability reporting worldwide. Its specific mission is to entrench sustainability reporting as a useful and robust practice both for organizations and for their stakeholders (GRI, 2008). Founded in 
1997, GRI has since 2000, developed generally accepted guidelines encompassing all the three spheres of sustainability (economic, environmental, and social) for reporting on business sustainability to a level equivalent to that of auditable financial reporting in terms of rigour and comparability (Willis, 2003). GRI has developed four sets of guidelines relating to $\langle$ IR>. The first GRI Guidelines (G1) was published in 2000; two years later, at the World Summit on Sustainable Development (WSSD) in Johannesburg, the second version of the Guidelines (G2) was released. The Sustainability Reporting Framework (G3) was published in 2006 and updated in 2011. G3 draws upon the principles included in the IASB's (2010a) Conceptual Framework for Financial Reporting, widening its application to include sustainability issues. G4:Reporting Principles and standard disclosures(2015) provided guidelines relating to qualitative characteristics regarding report quality, such as balance, comparability, accuracy, timeliness, reliability and clarity and guidance on how to set the report's boundaries in terms of reporting on the basis of materiality of impact and the level of influence, or control, over reporting entities. These guidelines expect company reports to include coverage of business strategy objectives, the company profile, the management approach, and a list of key performance indicators, and other disclosures such as (i ) Labour practices and decent work; (ii) Human rights strategy and management; (iii) Society; and (iv) Product responsibility. According to KPMG (2013) the GRI (and possibly the Sustainability Accounting Standards Board (SASB)) remain the most widely used voluntary reporting framework and in the absence of countryspecific regulatory requirements, plays an important role in improving consistency in sustainability reporting and the quality of disclosure.

The South African Integrated Reporting Committee (IRC):In 1994 the King Report on Corporate Governance (King I) was published by the Institute of Directors in Southern Africa (IoDSA).The Committee was chaired by Professor Mervyn King, a former High Court judge. King I, incorporated a Code of Corporate Practices and Conduct aimed at promoting the highest standards of corporate governance in South Africa. Over and above the financial and regulatory aspects of corporate governance, King I called for an integrated approach to good governance in the interests of a wide range of stakeholders. Although groundbreaking at the time, the evolving global economic environment informed an update of King I in 2002 (i.e., King II). The King II Report (2002)reiterated the recognition and adoption of the concept of sustainability in business to mean the achievement of balanced and integrated economic, social and environmental performance ("triple bottom line")1. King II also sought to provide indicative and inspirational guidelines to companies that recognise the importance of the relationship between an enterprise and the community in which it exists and therefore seek to improve on its disclosure practices. The King III (2009) Report contained a principle that strategy, risk, performance, and sustainability are inseparable and recommended that companies prepare an integrated report to reflect this. Accordingly, the Report required that organisations not only produce an integrated report in place of an annual financial report and a separate sustainability report (Viser, Matten, Pohl \& Tolhurst, 2010) but also create sustainability reports according to the Global Reporting Initiative's Sustainability Reporting Guidelines (G3). Furthermore,

\footnotetext{
${ }^{1}$ In a later interview, Mervyn King considered that the King II report was wrong in including sustainability as a separate chapter, leading companies to report on it separately from other factors.
} 
all listed companies on the Johannesburg Stock Exchange (JSE) are required to produce an integrated report or explain its absence. King IV Report was published on 1st November 2016; it incorporated all the key elements to be included in an integrated report. These are: (i) a concise overview of the organisation's structure, including governance and its main activities; (ii) a description of material risks and opportunities, based on a review of financial, social, environmental, economic, and governance issues; (iii) a description of the strategic objectives of the business as influenced by an assessment ofthe external environment and internal resource constraints; and (iv) an account of the organisation's performance based on its strategic objectives in terms of key performance and risk indices. The key concerns of stakeholders in the IRC (2011) discussion paper are therefore seen to include the ability of business leaders to strategically assess the opportunities, threats and key risks facing the company and to responsibly govern and manage the available resources entrusted to them in the delivery of sustainable performance. The discussion paper also suggests that in order to scrutinise the board of directors effectively, stakeholders need to expect a much wider range of performance metrics and risk indices from management than previously used, and a much greater accountability about how the business sets and meets its objectives.

The Prince of Wales Accounting for Sustainability Project: The Prince of Wales determined that accountants have a key role to play in helping organisations effectively measure and account for their environmental and social performance. Consequently, the Prince of Wales sponsored an Accounting for Sustainability Forum (A4S) (2007; 2009) in which a high level meeting of investors, standard setters, companies, accountancy bodies, and UN representatives was convened. An aim of A4S is to develop practical tools to enable environmental and social performance to be better integrated into the core strategy and financial performance of organisations. Over the following years A4S developed guidance for what it referred to as "connected reporting" wherein organisations were expected to draw the attention of report readers to the main connections between those social, environmental and economic actions and outcomes that are material for the reporting organisation (Hopwood, Unerman \& Fries, 2010).

In 2010, the GRI, the A4S and the International Federation of Accountants (IFAC) jointly partnered to found the International Integrated Reporting Council (IIRC) ${ }^{2}$ to develop integrated reporting globally as a decision-making model illustrating how sustainability issues could be effectively taken into account in decision making. In the same year, (i.e., 2010), the Integrated Reporting Committee (IRC) of South Africa was formed by the Institute of Directors in Southern Africa (IoDSA) under the Chairmanship of Professor Mervyn King to provide the best possible practice of integrated reporting in South Africa (the first country to make the application of $\langle\mathrm{IR}\rangle$ compulsory for all listed companies on the JSE).

International Accounting Institutions (IFAC, IASB\&IAASB): To place IR in a wider context, IFAC (2010) issued a consultation paper, which identified the roles of professional accountants in business and then identified eight drivers of sustainable

\footnotetext{
${ }^{2}$ IIRC also includes heads of IASB, FASB, IFAC, IOSCO, and the CEOs of the Big Four audit firms (Deloitte, E \& Y, and KPMG \& PwC), the major British professional accountancy bodies and CFOs of major multi-nationals, such as Nestle, Tata and HSBC.
} 
matters that should be reported upon. IFAC described accountants as creators of value, enablers of value, and preservers of value and reporters of value. These labels summarise the role of the accountant as sustainably creating, supporting and reporting value for the business. The eight key drivers of sustainability relating to these roles were identified as: (a) customer and stakeholder focus; (b)effective leadership and strategy; (c) integrated governance, risk and control; (d) innovation and adaptability; (e) financial management; (f)people and talent management; (g) strategy execution; and (h) effective and transparent communication.

To complement the above (IFAC) consultation paper, the International Accounting Standards Board (IASB) (2010b) published a Practice Statement, which provided a framework for the presentation of management commentary. The Practice Statement outlined the purpose, principles and presentation of such information. The main elements of this paper included commentary on the nature of the business, objectives and strategies, resources, risks and relationships, results and prospects, and performance measures and indicators. The International Auditing and Assurance Standards Board (IAASB) (2011) also produced a discussion paper which dealt with the audit implications of increased subjectivity introduced by IR. It was argued that with the adoption of IR, more prospective narrative and much more qualitative (rather than quantitative) information is included which "blurs boundaries" and increases subjectivity.

Following the above publications, IFAC (2011) also produced a Sustainability Framework 2.0: Professional Accountants as Integrators, which focused on three broad IR perspectives: the business strategy perspective; the operational perspective; and the reporting perspective. Within the strategy perspective, such areas as vision and leadership, stakeholder engagement, goal setting and risk management are the suggested content of integrated reports. The operational perspective focuses on performance management and sustainability issues, including waste management and carbon foot printing. Finally, the reporting perspective addresses organisational reporting strategies, sustainability impacts, and enhanced transparency through additional narrative reporting, within materiality thresholds.

All of the above statements, discussion papers, guidelines and frameworks effectively recommend the inclusion of more strategic, forward-looking and relevant information for decision-making or support purposes, as compared with the traditional stewardship reporting model. To emphasise the decision-support role of integrated reporting and the broader base of stakeholders for whom IR is intended, the concept of the 'greatest shareholder' as a user of such reports is described in the IIRC (2011) framework paper as follows:

The greatest shareholder today is no longer the wealthy family, but it is the individual via his or her financial institution and pension fund. The same individual is also the employee of the company; the customer who chooses between the products of company A or company B; the voter for the government of the day and for the trustee of the pension fund. In addition, the individual is also a citizen of a country who expects his or her neighbour to act as a decent 
citizen, and as a consequence today, the individual citizen expects the corporate citizen to act as a decent citizen. (Mervyn King, Chairman, International Integrated Reporting Committee)

International Integrated Reporting Council (IIRC): The IIRC (2011) released a Discussion Paper "Towards Integrated Reporting: Communicating Value in the 21st Century. The Discussion Paper was the first step in the development of the International Integrated Reporting Framework (2013); this was preceded by an Exposure Draft (ED) published in 2012.It sought to build on existing developments in reporting such as the international convergence of accounting standards, sustainability guidance published by GRI, and IFRS Practice Statement: Management Commentary. Figure 1 shows that an integrated report is based on three fundamental concepts,five guiding principles and six main components:

(i). Fundamental Concepts that mutually enforces and underpins $<$ IR $>$ are:

a) Value creation for the organisation and for others. An organisation's activities, its interactions and relationships, its outputs and the outcomes for the various capitals it uses and affects and influences its ability to continue to draw on these capitals in a continuous cycle.

b) The capitals. The capitals are the resources and the relationships used and affected by the organisation; identified in the <IR > Framework as financial, manufactured, intellectual, human, and social, and relationship, and natural capital. However, these categories of capital are not required to be adopted in preparing an entity's integrated report, and an integrated report may not cover all capitals - the focus is on capitals that are relevant to the entity

c) The value creation process. At the core of the value creation process is an entity's business model, which draws on various capitals and inputs, and by using the entity's business activities, which creates outputs (products, services, by-products, waste) and outcomes (internal and external consequences for the capitals).

(ii) Guiding Principles that inform the content of an integrated report and how information is presented are five:

a) Strategic focus- providing insight into the organisation's strategic objectives, and how those objectives relate to its ability to create and sustain value over time and the resources and relationships on which the organisation depends.

b) Connectivity of information - showing a holistic picture of the combination, inter-relatedness and dependencies between the factors that affect the organisation's ability to create value over time

c) Future Orientation- management's expectations about the future, as well as other information to help report users understand and assess the organisation prospects and the uncertainties it faces

d) Responsiveness and Stakeholder Inclusiveness - insight into the nature and quality of the organisation's relationships with its key stakeholders and how and to what extent the organisation understands, takes into account and responds to their needs. 
e) Conciseness , Reliability and Materiality - disclosing information that is material to assessing the organisation's ability to create and sustain value in the short, medium and long-term

(iii) Content Elements to be included in an integrated report expressing the organization's unique value creation story and making their interconnections apparent, rather than appearing as isolated, standalone sections; six elements are identified:

a) Organisational overview and business model - What is the organisation's business model? What does the organisation do and what are the circumstances under which it operates?

b) Governance and remuneration - How does an organisation's governance structure support its ability to create value in the short, medium and long term?

c) Operating context including risks and opportunities - What are the specific risk and opportunities that affect the organisation's ability to create value over the short, medium and long term and how is the organisation dealing with them?

d) Strategy and resource allocation - Where does the organisation want to go and how does it intend to get there?

e) Performance - To what extent has the organisation achieved its strategic objectives for the period and what are its outcomes in terms of effects on the capitals?

f) Future outlook - What challenges and uncertainties is the organisation likely to encounter in pursuing its strategy, and what are the potential implications for its business model and future performance?

Fig. 1 show that the main headings and principles in this framework overlap considerably with many of the headings used within earlier work (notably the IFAC Sustainability Framework, and the IASB's Practice Statement) and the other discussion papers. All consistently contain references to such elements as future outlook, strategic objectives, high-level operating context, stakeholder engagement, opportunities and risk assessments, governance issues and business performance indicators or metrics. 


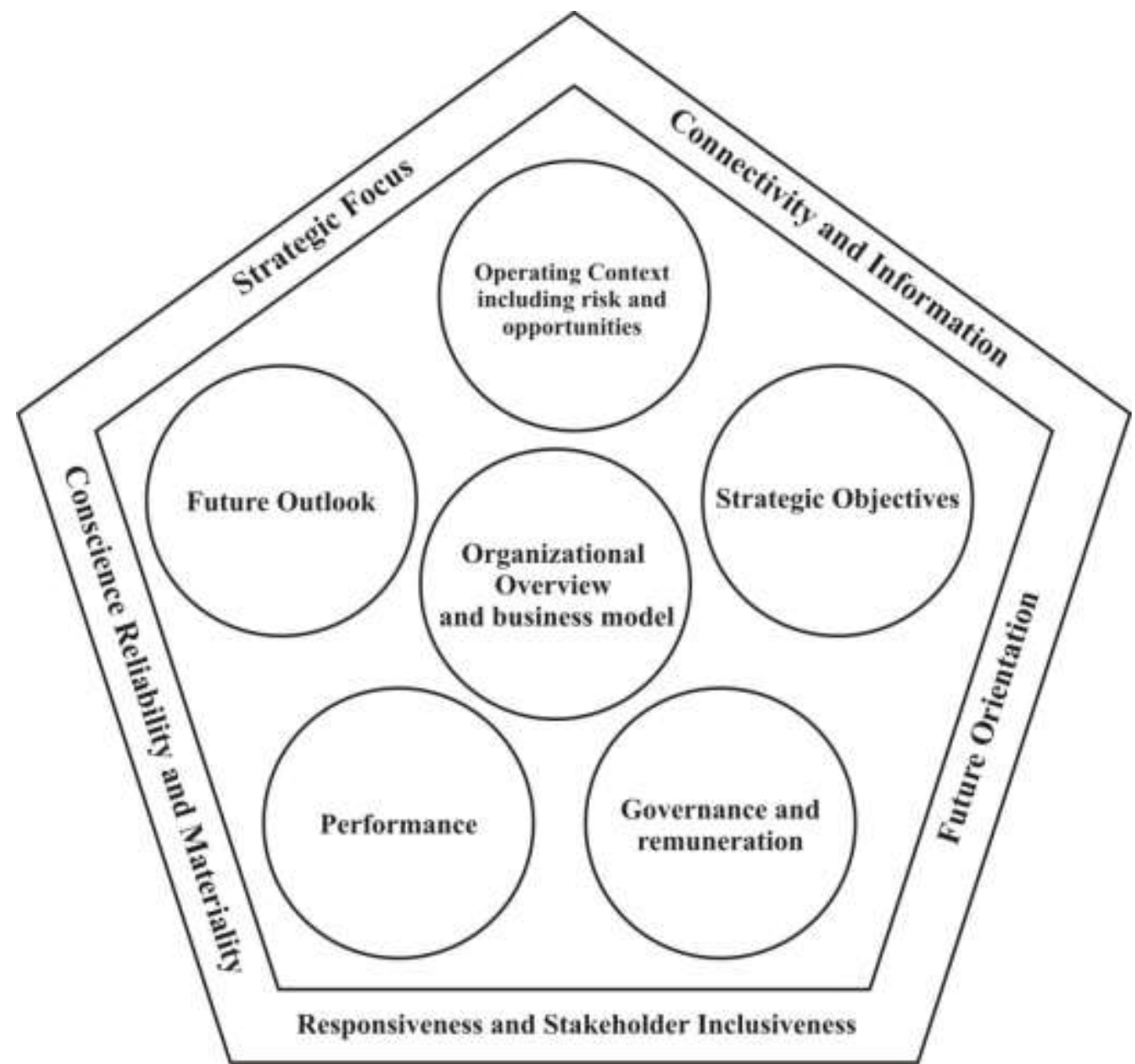

Figure 1: Integrated Reporting Framework.

Source: The IIRC Framework (2013)

\section{Implications of $\langle$ IR $>$ on Accounting Curriculum}

Traditionally, accounting programmes focus on teaching for-profit financial and management accounting with the idea of maximizing profit and don't take into account the impact of those practices on the stakeholders in their community. Consistent with this tradition, accounting principles have been mostly about recognising, measuring and valuing assets, liabilities, income and expenditure; accounting practice has tended to concentrate more on the shorter-term financial performance metrics through its focus on the periodic recording, processing, summarising and reporting of financial information for shareholders. Consistent with this orientation, the traditional accounting curriculum has been focused mainly at the transactional level of the business with greater emphasis placed on the financial accounting and reporting functions. There has also been more focus on external audit rather than on developing proactive systems of governance, internal control or risk management.

However, there is increasingly an understanding that financial information does not sufficiently discharge organizational accountability to members of society who are demanding an account of the social and environmental impacts of companies' and other organizations' activities. As a result, organizations report ever more social and 
environmental information, and there are simultaneous movements towards providing the information in an integrated fashion, showing how social and environmental activities influence each other, members of society and the financial aims of the organization. The provision of information in an integrated fashion, i.e., integrated reporting takes a more sustainable longer-term view of the business and its ability to affect and be affected by its environment. <IR>and the principles behind it suggests therefore, that a modern accounting curriculum must include learning outcomes that relate to the key suggested elements of an integrated report including greater synthesis of both quantitative and qualitative information as proposed consistently in the various discussion papers and frameworks highlighted in this paper, particularly within the King IRC, the GRI, IFAC and IIRC frameworks. Thus a synthesis of the recommendations and guidance by these institutions should form a defined set of highlevel outcomes that could form the basis of a high-level structure for a twenty-firstcentury accounting curriculum. Owen (2013: 350) summarises the outcomes of IR as a basis for an accounting curriculum for a twenty-first- century corporate/integrated reporting model, for both professional and university education as follows:

a) Review the organisation, its governance structure, its core activities and business model, and how it creates and adds value for stakeholders.

b) Assess risks and opportunities, as identified from an evaluation of financial, social, economic and environmental and governance issues.

c) Identify and evaluate an entity's strategic objectives as informed by (a) and (b) above, taking into account sustainability issues.

d) Evaluate the organisation's core competences to achieve these objectives sustainably in (c) above, and justify how achievement of these objectives is monitored and controlled, using short- medium- and longer-term key performance indicators.

e) Account for the sustainable performance of the organisation, using financial and non-financial key performance measures of its material social, environmental, economic, and financial impacts on key stakeholders.

f) Explain the alignment of remuneration policy relating to senior executives and evaluate their performance in relation to (e) above.

When IR and sustainability principles become mainstream reporting models rather than abstract or inspirational academic concepts, greater synthesis of previously discretely taught accounting courses could be given more prominence. For example, it might be sensible to combine principles of performance management with elements of strategy, risk, governance and finance, including selected material on internal audit and control principles. More qualitative reporting and assessment of entities could be introduced, based on 'substance over form' rather than the current transactional emphasis on detailed accruals-based financial adjustments. A greater focus on more holistic valuebased financial reporting models such as economic value added (EVA) (Stewart, 1991), Shareholder Value Added (Rappaport, 1986) and free cash flow accounting (FCF) as underpinned by fundamental economic and risk-based models such as portfolio theory and the capital asset model (CAPM) may be required. 
Regarding the content of curricula, more emphasis on business strategy, governance and agency will be required so that accountants develop a greater sense of corporate social responsibility and ethics, and become more aware of their obligations to stakeholders and the wider public interest. The balance of emphasis on external financial reporting in the narrower sense may well diminish in the future and in its place a more holistic approach to reporting, based on internal management accounting information and performance management and finance based metrics and measurements, could emerge. Therefore, in the future, it is likely that there may be fewer modules called financial reporting and more with general titles such as 'corporate reporting' or even 'integrated reporting' in which the syllabi focus much more on the qualitative and the prospective aspect of external reporting than on presenting detailed historical data. The accounting curriculum will also need to contain more emphasis on performance and financial management at all levels of the organisation and on the link between performance management, strategy and external reporting.

Corporate reports will include more information on business outlook and strategy by presenting long-term plans and even broad budgetary information (taking into account information sensitivity analysis). The new emphasis in such reports will mean that syllabi will need to include analysis of high-level variance and exceptions analysis in financial and performance management terms. This will be necessary to hold directors more accountable for discrepancies between actual performance and impacts, compared with forecasts already published, and to recommend performance improvements in the future.

Regarding assessment, more extensive use may need to be made of the integrated case study approach and of other integrated approaches. Learners will need to demonstrate higher-level synthesis and evaluation skills. They will need to analyse more unstructured information, financial, quantitative and qualitative, from a greater variety of sources, to present a more rounded evaluation of the position, performance and impacts of an entity. The focus of such assessments under the $<\mathrm{IR}>$ model of reporting will tend to become more strategic and tactical rather than transactional. Learners will therefore need to become more adept at business rather than purely financial analysis. They will need to appreciate the value of using information for its predictive capability, for prospective evaluation and for its remedial and corrective purposes, than from the more passive stewardship perspective.

\section{Integrated Reporting in Academic and Professional Education}

Before proceeding, the relationship between integrated reporting and sustainability reporting will be addressed. Sustainability reporting provides an important basis for the integrated reporting process. Sustainability accounting contributes the methods and data that are crucial for the preparation of an integrated report. Sustainability reports seek to provide detailed information regarding a company's economic, social and environmental impacts for a broad audience, while integrated reports are more focused on communicating, primarily to providers of financial capital, material financial and the non-financial factors that contribute to value creation. 
GRI (2013) determined that while analytical and integrated thinking are required to prepare an integrated report, a significant challenge in its preparation is the ability to break down established silos and link all the information in a way that the value creation story is told. It is reasoned that the skills needed to successfully advance <IR >efforts must be cultivated in accounting curricula where individuals' leadership skills are developed. Based on this reasoning, leading global professional accountancy bodies have already fully recognised and embraced this philosophy and incorporated principles of Sustainability and Integrated Reporting within their curriculum at the professional level. We examine curricula of ACCA, CIMA and AICPA, as it relates to integrated reporting.

The Association of Chartered Certified Accountants (ACCA) is a global body for professional accountants. ACCA's Curriculum Policy Statement confirms its belief that:

Sustainability issues should be fully integrated into the professional examination curriculum so that future generations of accountants are better equipped to recognise the challenge that sustainable development poses to their organisations. ACCA also believes that accountants will need to understand the many different ways in which sustainability matters will permeate their future business careers - whether through environmental taxation considerations, investment appraisal decisions, financial reporting of carbon assets, risks and liabilities, and/or the management of reputational risk.

Following from this belief, the ACCA restructured its curriculum to examine the elements of integrated reporting directly or explicitly in its curriculum. The contents and structure of the core content elements of the IIRC Framework ${ }^{3}$ are linked and embedded within the seven professional level papers (ACCA, 2011; ACCA, 2014).In addition, 11 of 16 of ACCA's examination syllabuses embed ethical and sustainability principles and examiners are encouraged to introduce ethical and environmental dimensions to support technical requirements to examine candidates' values and judgement as well as their knowledge. The audit examinations also cover governance aspects related to the audit and assurance functions including risk management, internal audit and internal controls. In addition, ACCA students are required to complete practical experience requirements, which include demonstrating specific performance objectives relating to the principles underlying integrated reporting.

Similarly, the Chartered Institute of Management Accountants (CIMA), the world's largest and leading professional body of management accountants, included integrated reporting in its revised syllabus from 2015. The CIMA affirms and recognises that "Integrated Reporting ( $\langle\mathrm{IR}\rangle$ ) offers a new opportunity and the best possible way now available to tell the value creation story by drawing on existing information to succinctly bring together insights and information from across the business for investors and others". The CIMA syllabus comprises of 12 computer-based examinations split

\footnotetext{
${ }^{3}$ The core content elements of the IIRC Framework are: organisational overview, governance, opportunities and risks, strategy and resource allocation, business model, diverse capital base \&future outlook
} 
into three subject pillars as well as three levels which test operational, management and strategic competencies. CIMA's study and robust assessment methods mean that the real-life skills and competencies employers need are woven into the syllabus. The syllabus is strong on the core accounting skill, but also includes Big Data, sustainability, integrated reporting and finance function transformation. CIMA students also study risk, as well as costing and cost management.

The American Institute of Certified Public Accountants (AICPA) is arguably the most influential body of professional accountants in the world. The AICPA (2002) approved the creation of a Special Committee on the Business Reporting Model of the Future to transform today's corporate reporting to the reporting model of the future. The framework that evolved from this effort ultimately informed the development of the International <IR> Framework, which the AICPA strongly supports. The AICPA's primary focus in the area of $<\mathrm{IR}>$ remains education and advocacy to help members and the profession worldwide to adopt and benefit from $\langle\mathrm{IR}\rangle$. For example, in July 2014, the AICPA and CIMA took part in a survey to help develop a better understanding of the $\langle$ IR $>$ value. The joint AICPA/CIMA venture established the Chartered Global Management Accountant (CGMA) designation to elevate and build recognition of the profession of management accounting, integrating thinking, creating and preserving value which is at the heart of high-quality decision-making. CGMA designation holders ${ }^{4}$ have an important role to play in advocating more holistic consideration of outcomes and impacts that assist organisations to report more effectively and act as a tool to help refine the organisational value creation process.

By including sustainability accounting and integrated reporting in their syllabi, the professional accountancy bodies are assured that their members are complete finance professionals with the capabilities and competences necessary to work in the present day "sustainable capitalism" (Mitra, Gadhok, Salhotra \& Agarwal, 2011; Jones, 2017; Ikerd, 2005) that requires a more holistic view of corporate reporting.

Regarding academic accounting courses in the university, some universities have incorporated integrated/sustainability reporting principles within existing curriculum or have added optional stand-alone sustainability/integrated reporting modules to the existing curriculum (Mburayi \& Wall, 2018). However, incorporation into or addition of sustainability/integrated reporting in the accounting and finance curricula is not pervasive. Pippin, Wong, Weber and Bergner (2016) found that fewer than 2\% of USA universities currently offer embedded or stand-alone accounting courses in sustainability/integrated reporting. Mburayi and Wall (2018) suggest that accounting, finance and economics disciplines are based on theoretical assumptions which are not consistent with sustainability. In particular, theoretical underpinning of finance and economics disciplines is largely based on the assumption of investor primacy, efficient markets and rational expectations. Therefore the integration of sustainability (with its different aspirations) in accounting and finance curricula will be resisted by faculty members. Different explanations have been provided for the low supply of 
sustainability accounting courses. Pippin et al. (2016) explained the low supply of sustainability accounting courses in terms of lack of (a) available faculty, time or financial resources to create and teach an entire course about sustainability/integrated reporting in accounting; (b) instructional materials and textbooks and (c) demand for graduates with sustainability reporting knowledge among US employers. At the same time, Pippin et al. (2016) expect that global trends in sustainability and integrated reporting would provide an impetus for educating accounting students based on the $<\mathrm{IR}>$ learning outcomes. In other words, as the demand for sustainability reporting increases and teaching materials for sustainability/integrated accounting courses becomes more readily available, courses in sustainability/ integrated reporting will become more widespread.

\section{Sustainability Accounting and Integrated Reporting in Nigeria}

Sustainability disclosure in Nigeria is voluntary and a number of Nigerian companies are known to have performed social activities in their area of operations (Michael \& Oluseye, 2014; Asaolu, Agboola, Ayoola, \& Salawu, 2011; Nzewi, Nzewi, \& Okereoti, 2013). However, some financial regulators in Nigeria have made concerted efforts to promote sustainable business practices in their various industries. For example, : (i) the Sustainable Banking Principles of the Central Bank of Nigeria (CBN), (ii) the Sustainable Stock Exchange Initiative of the Nigerian Stock Exchange (NSE), and (iii) the Sustainable Finance Principles promoted by the Financial Services Regulatory Coordinating Committee (FRSCC).In 2015, the Nigeria Stock Exchange sponsored the Nigerian Capital Market Sustainability Conference (NCMSC). In that conference, Jeremy Grist, Ernest and Young's Director of Climate Change and Sustainability Services emphasized how financial reporting created the market we have today, and how Integrated Reporting will create the society we want to have tomorrow".

Regarding integrated reporting, no single Nigerian company is known to have reported under the IIRC framework (Tijani, Gboyega \&Kayode, 2013; Umoren, Udo \& George, 2015; Okaro \& Okafor, 2017). This situation may be explained by the absence of regulatory compulsion for reporting under the <IR> Framework in Nigeria; the Financial Reporting Council of Nigeria (FRCN) is yet to mandate sustainability/integrated reporting for listed companies. This is in contrast to South Africa, for example, where all listed companies are required to produce an integrated report or explain why in the event that an integrated report is not filed. In addition, Nigerian tertiary institutions are yet to upgrade their curricula to reflect the current thinking in integrated reporting and ensure a pool of future accountants that will sustain the IR drive (Babajide, Imoleayo \& Uwalomwa, 2015).

Not all hope is lost: The International Accounting Standards Board (IASB) is discussing the place of non-financial information in corporate annual reporting. Such nonfinancial information includes integrated sustainability reporting information. With time, the FRCN will discover that internationally, financial reporting regulation is shifting towards integration of financial and non-financial reporting. In addition, it is envisaged that the desire for competitive advantage over rivals will drive Nigerian companies to adopt IR. This development points to real prospects of IR being made 
mandatory in the near future for Nigerian companies. With these developments, positive prospects for integrated reporting in Nigeria are expected.

\section{Integrated Reporting in Accounting Curriculum of Nigerian Universities}

The Nigerian National University Commission (NUC) is the government agency that regulates curriculum development and teaching methodology for all programmes offered in Nigerian Universities. From 2014, the NUC merged the content-based minimum academic standards (MAS) and outcome-based benchmark statements into new documents referred to as the Benchmark Minimum Academic Standards (BMAS). The resultant documents, an amalgam of the outcome-based Benchmark statements and the content-based MAS clearly enunciates the learning outcomes and competencies expected of graduates of each academic programme, (including accounting) without being overly prescriptive while at the same time providing the requisite flexibility and innovativeness consistent with institutional autonomy. For each degree programme, the document contains suggestions of the status of each course in terms of compulsory, required and elective. Universities are encouraged to take due cognizance of the BMAS while bringing necessary innovation into the content and delivery of their programmes towards achieving their overall objectives and goals. The NUC expects that the BMAS document will serve as a guide to the universities in the design of curricula for their programmes in terms of the minimum acceptable standards of input, process as well as measurable benchmark of knowledge, skills and competences expected to be acquired by an average graduate of each of the academic programmes.

In relation to undergraduate Accounting degree programmes therefore, the NUC's charge to universities is to take due cognizance of the indicated BMAS while bringing necessary innovation into the content and delivery of their programmes towards achieving their overall objectives and goals. Considering the allowed latitude, Accounting Departments can introduce learning outcomes and/or principles of $\langle\mathrm{IR}\rangle$ into existing course offerings as suggested in section 4.At the least, the universities can integrate the three fundamental concepts, five guiding principles and six main components (see section 3v) across the courses of their Accounting bachelors' degree programmes. Where it is preferred, an elective stand-alone $\langle\mathrm{IR}\rangle$ model could be offered to expose interested students to the basic principles of the $\langle\mathrm{IR}\rangle$ framework discussed and presented in Fig. 1.

\section{CONCLUSION}

Several organisations including the GRI, the South Africa-based IRC, the A4S, the IIRC and other international accounting organisations have heavily promoted integrated reporting $(<\mathrm{IR}\rangle)$ as the communication vehicle that provides concise, futureoriented and strategically relevant information that integrates financial, social and environmental elements to providers of the capitals and other interested parties. These organisations articulated more or less similar principles and frameworks regarding $<$ IR $>$. In the event that IR becomes main-stream, it is reasoned that there would a need to review professional and university accounting curricula to meet the suggested corporate reporting protocols/principles. 
In view of the suggested learning outcomes, fundamental concepts, guiding principles and main components of an integrated report as enunciated in the paper, it is envisaged that the "new" accounting curricula would focus more on the longer-term than the shorter-term, corporate strategic outlook than operational or transactional processes; present more prospective rather than retrospective analysis; include more qualitative commentary as well as quantitative information; and report on wider business performance metrics rather than on narrower external financial reporting data or audit compliance.

Leading global professional accountancy bodies (e.g., ACCA \& CIMA) have already fully incorporated integrated reporting principles within their curriculum at the professional level. Regarding academic accounting courses in the university, few universities outside Nigeria have incorporated integrated/ sustainability reporting principles or learning outcomes within existing curriculum or have added optional stand-alone sustainability/integrated reporting modules to the existing curriculum (Mburayi \& Wall, 2018). In Nigeria, no single company is known to have reported under the IIRC framework (Tijani, Gboyega \& Kayode, 2013; Umoren, Udo \& George, 2015; Okaro \& Okafor, 2017). Similarly, no Nigerian tertiary institution is known to have upgraded their curricula to reflect the current thinking in integrated reporting (Babajide, Imoleayo \& Uwalomwa, 2015).

Regarding assessment, more extensive use may need to be made of the integrated case study approach and of other integrated approaches ${ }^{5}$. Learners will need to demonstrate higher-level synthesis and evaluation skills. They will need to analyse more unstructured information, financial, quantitative and qualitative, from a greater variety of sources, to present a more rounded evaluation of the position, performance and impacts of an entity.

NUC has allowed Accounting Departments much latitude to take due cognizance of the indicated BMAS while bringing necessary innovation into the content and delivery of their programmes towards achieving their overall objectives and goals. Accounting departments of Nigerian universities could therefore, incorporate principles of $\langle\mathrm{IR}\rangle$ into existing course offerings as suggested in section 4 or offer it as a stand-alone elective course.

\section{References}

Accounting for Sustainability (2010). Connected reporting. http://www.connectedreporting.accountingforsustainability.org

Adams, C. A. \& Frost, G. R. (2008). Integrating sustainability reporting into management practices. Accounting Forum. 32, (4), 288-302.

Adams, C., Frost, G. and Webber, W. (2004). Triple bottom line: A review of the literature. In Henriques, A. and Richardson, J. (Eds), The triple bottom line, does it all add up? Assessing the sustainability of business and CSR, Earthscan, London, pp. 17-25.

\footnotetext{
${ }^{5}$ The Chartered Institute of Accountants of Nigeria (ICAN) already examines "Integrated Case Study" at the professional level.
} 
Association of Chartered Certified Accountants, ACCA (2011). Integrated reporting: The future of corporate accounting? Roundtable discussion held at Singapore on 14 October.

Association of Chartered Certified Accountants, ACCA (2014). ACCA embeds integrated reporting http://www.accaglobal.com/za/en/student/acca-qualstudent-journey/sa/features/acca-embeds-integrated-reporting.html

Barth, M. E., Cahan, S. F., Chen, L., \& Venter, E. R. (2017). The economic consequences associated with integrated report quality: Capital market and real effects. Accounting, Organizations and Society, 62, 43-64.

Beck, C., Dumay, J., \& Frost, G. (2015). In pursuit of a 'single source of truth': from threatened legitimacy to integrated reporting. Journal of Business Ethics, 1-15.

Bekefi, T., Epstein, M. J. \& Yuthas, K. (2008). Management accounting: Guideline managing opportunities and risks. The Society of Management Accountants of Canada (CMA Canada), the American Institute of Certified Public Accountants, Inc. (AICPA) and The Chartered Institute of Management. Accountants. (CIMA).http://www.cimaglobal.com/Documents/ImportedDocuments/cid_ma g_managing_opportunities_and_risk_march08.pdf.pdf

Bhimani, A., \& Langfield-Smith, K. (2007). Structure, formality and the importance of financial and non-financial information in strategy development and implementation. Management Accounting Research, 18(1), 3-31.

Boje,D M, (2016), Critique of the Triple Bottom Line.In Grace Ann Rosile (ed.) Tribal Wisdom for Business Ethics, pp.181 - 198

Burritt, R. L., \& Schaltegger, S. (2010). Sustainability accounting and reporting: Fad or trend? Accounting, Auditing \& Accountability Journal, 23(7), 829-846.

Camilleri, M. A. (2017). Corporate sustainability, social responsibility and environmental management: An introduction to theory and practice with case studies. Heidelberg- Germany: Springer.

Crowther, D. (2016). A social critique of corporate reporting: Semiotics and web-based integrated reporting. Abington- Oxford, UK: Routledge.

de Villiers, C., Rinaldi, L. and Unerman, J. (2014). Integrated reporting: insights, gaps and an agenda for future research, Accounting, Auditing \& Accountability Journal, 27 (7), 1042-1067.

Deloitte (2011). Integrated Reporting: Navigating your way to a truly integrated report.

Eccles, R. G. \& Krzus, M. (2010).One Report: Integrated Reporting for a Sustainable Strategy. John Wiley \& Sons: US.

Elkington, J. (1994). Towards the sustainable corporation: Win-win-win business strategies for sustainable development, California Management Review, 36(2), 90-100.

Elkington, J. (1998).Cannibals With Forks: The Triple Bottom Line of 21st Century Business, Gabriola Island and Stony Creek, CT: New Society Publishers.

Elkington, J. (2004). Enter the triple bottom line. In Henriques, A. and Richardson, J. (Eds), The Triple Bottom Line, Does it All add Up? Assessing the Sustainability of Business and CSR, Earthscan, London, pp 1-16.

Flower, J. (2015). The international integrated reporting council: A story of failure. Critical Perspectives on Accounting, 27, 1-17. 
Giovannoni, E. \& Maraghini, M.P. (2013). The challenges of integrated performance measurement systems: integrating mechanisms for integrated measures, Accounting Auditing \&Accountability Journal, 26 (6), 978-1008.

Gökten, P. \& Marşap, B. (2017). Paradigm shift in corporate reporting; in Soner Gokten (ed), Accounting and Corporate Reporting - Today and Tomorrow, InTech Publishers, Rijeka, Croatia.PP.3-14.

Gray, R. (2006). Social, environmental and sustainability reporting and organisational value creation? whose value? Whose creation? Accounting, Auditing \& Accountability Journal, 19(6), 793-819.

GRI (2006). G3 - The sustainability reporting framework: http://www.deloitte.com/assets/Dcom

GRI (2008). Sustainability report: https://www.globalreporting.org/resourcelibrary/GRI-Sustainability-Report2007-2008.pdf

GRI(2013). Report or explain campaign forum. (Global Reporting Initiative) https://www.globalreporting.org/network/report-or-explain/Pages/default.aspx

GRI (2015). G4 guidelines - reporting principles and standard disclosures http://www.globalreporting.org/resourcelibrary

IAASB (2011).The evolving nature of financial reporting: Disclosure and its audit implications, IFAC.

IASB (2010a).Conceptual framework for financial reporting (the IFRS Framework), IFAC.

IASB (2010b). Management commentary: A framework for presentation, IFAC.

IFAC (2010). Competent and versatile: How professional accountants in business drive sustainable organizational success, New York: IFAC.

IFAC (2011) Sustainability framework 2.0: Professional accountants as integrators. New York: IFAC.

Ikerd, J. (2005).Sustainable capitalism: A matter of common sense. Bloomfield, CT: Kumarian Press Inc.

Integrated Reporting Committee (IRC) of South Africa (2011).Framework for Integrated Reporting and the Integrated Report, SAICA.

International Integrated Reporting Committee (IIRC) (2011).Towards Integrated Reporting: Communicating Value in the 21st Century,http://www.theiirc.org/wp-content/uploads/2011/09/IR-DiscussionPaper-2011_spreads.pdf

International Integrated Reporting Council (IIRC) (2018). Integrated report 2017 https://integratedreporting.org/integratedreport2017/index_desktop.html

IRC (2011).Framework for integrated reporting and the integrated report discussion paperhttp://www.sustainabilitysa.org/Portals/0/Documents/IRC\%20of\%20SA \%20Integrated\%20Reporting\%20Guide\%20Jan\%2011.pdf

Jones, G. (2017). Profits and sustainability. A history of green entrepreneurship. Oxford University Press.

Kaplan, R.S. \& Norton, D.P. (1996).The balanced scorecard. Boston, MA: Harvard Business School Press.

KPMG (2017). The road ahead: The KPMG survey of corporate responsibility reporting $2017 \quad$ http://integratedreporting.org/wp- 
content/uploads/2017/10/kpmg-survey-of-corporate-responsibility-reporting2017.pdf

KPMG. (2013). The KPMG survey of corporate responsibility reporting. https://www.researchgate.net/publication/280712152_The_KPMG_Survey_of _Corporate_Responsibility_Reporting_2013

Mburayi, L., \& Wall, T. (2018).Sustainability in the professional accounting and finance curriculum: an exploration. Higher Education, Skills and Work-Based Learning, 8(3), 291-311.

Mitra, B., Gadhok, S., Salhotra, S., \& Agarwal, S. (2011). The convergence of sustainable capitalism. 2011 IEEE International Professional Communication Conference.

Nixon, B. and Burns, J. (2012). The paradox of strategic management accounting, Management Accounting Research, 23(4), 229-244.

Norreklit, H. (2003). The balanced scorecard: What is the score? A rhetorical analysis of the balanced scorecard, Accounting, Organizations and Society, 28 (6): 591619.

Owen, G. (2013) Integrated reporting: A review of developments and their implications for the accounting curriculum, Accounting Education, 22(4): 340-356.

Parker, L.D. (2005). Social and environmental accountability research: A view from the commentary box. Accounting, Auditing \& Accountability Journal, 18, 842860.

Pippin, S., Weber, L., Wong, J., Bergner (2016) The Inclusion of Sustainability in the Accounting Curriculum. The CPA Journal https://www.cpajournal.com/category/magazine/june-2016-issue/

Rappaport, A. (1986).Creating shareholder value: The new standard for business performance, New York: Free Press.

Savitz, A. (2006). The triple bottom line. San Francisco: Jossey-Bass.

Slaper, T; Hall, T. (2011). The triple bottom line: What is it and how does it work? Indiana Business Review, 86(1), 4 -8.

Sridhar, K., \& Jones, G. (2012). The three fundamental criticisms of the triple bottom line approach: An empirical study to link sustainability reports in companies based in the Asia-Pacific region and TBL shortcomings. Asian Journal of Business Ethics, 2(1), 91-111.

Stewart, G. B., III (1991).The quest for value - The EVA management guide. New York: Harper Collins.

Wang, L., \& Lin, L. (2007). A methodology framework for the triple bottom line accounting and management of industry enterprises. International Journal of Production Research, 45(5), 1063-1088.

Willis, A. (2003). The role of the global reporting initiative's sustainability reporting guidelines in the social screening of investments. Journal of Business Ethics, 43(3): 233-237. 